\title{
SONHOS DE VIDA DA GESTANTE ADOLESCENTE: REFLEXÕES SOBRE O PAPEL EDUCATIVO DO ENFERMEIRO
}

\author{
LA VIDA ADOLESCENTE EMBARAZADA DREAMS: REFLEXIONES SOBRE EL \\ PAPEL DE LAS ENFERMERAS EDUCATIVOS
}

\author{
THE PREGNANT ADOLESCENT LIFE DREAMS: REFLECTIONS ON THE ROLE \\ OF EDUCATIONAL NURSES
}

\author{
Marina Patricio de ARRUDA ${ }^{1}$ \\ Nayara Alano MORAES ${ }^{2}$
}

RESUMO: A curiosidade sobre o tema surge no acompanhamento do pré-natal de adolescentes e de reflexões de uma profissional de enfermagem que atua na "Estratégia de Saúde da Família" (ESF). Os sonhos se apresentam como uma perspectiva de vida, que mesmo resguardados pelas gestantes adolescentes podem conter possibilidades reflexivas para projeções futuras. O objetivo do estudo foi refletir sobre os sonhos de vida de adolescentes grávidas e as possibilidades para ações educativas em saúde. Pesquisa de caráter qualitativo, desenvolvida por meio de um estudo de caso por acessibilidade, tipo de amostragem muito utilizada em estudos exploratórios ou qualitativos, na qual o pesquisador escolhe os participantes aos quais tem acesso. $\mathrm{O}$ estudo foi realizado com quatro gestantes adolescentes cadastradas numa USF de um município de médio porte de $\mathrm{SC}$, por meio de oficinas pedagógicas. Os resultados mostraram que família e escola configuram-se como espaços de conflito para as gestantes adolescentes. Os desenhos e narrativas sobre os sonhos de vida das gestantes adolescentes fizeram refletir sobre a importância do papel educativo do enfermeiro na vida dessas adolescentes carentes de cuidados, informações e apoio.

PALAVRAS-CHAVE: Gestante adolescente. Sonhos de vida. Papel educativo do enfermeiro. Escola e família.

RESUMEN: La curiosidad por el tema surge en el seguimiento de los adolescentes prenatales y reflexiones de un asilo de ancianos actos profesionales en la "Estrategia Salud de la Familia" (FSE). Los sueños se presentan como una perspectiva de la vida que incluso vigilado por las adolescentes embarazadas puede contener posibilidades reflexivas para las proyecciones futuras. El objetivo del estudio era reflexionar sobre los sueños de la vida de las adolescentes embarazadas y las posibilidades de acciones educativas en materia de salud. investigación cualitativa, desarrollado a través de un estudio de caso para la accesibilidad, tipo de muestra ampliamente utilizados en la exploración o

\footnotetext{
${ }^{1}$ Universidade do Planalto Catarinense (UNIPLAC), Lages - SC - Brasil. Professora e pesquisadora junto aos Programas de Pós-graduação Stricto Sensu da Universidade do Planalto Catarinense, PPGE e PPGAS. Email: marininh@terra.com.br

${ }^{2}$ Universidade do Planalto Catarinense (UNIPLAC), Lages - SC - Brasil. Enfermeira e mestre em Educação pela Universidade do Planalto Catarinense. E-mail: nayalanomoraes@ gmail.com
}

RIAEE - Revista Ibero-Americana de Estudos em Educação, Araraquara, v. 13, n. 2, p. 822-838, abr./jun., 2018. E-ISSN: $1982-5587$. 
cualitativos estudios, en el que el investigador elige a los participantes que tienen acceso. El estudio se realizó con cuatro adolescentes embarazadas inscritas en USF un municipio de tamaño medio de SC a través de talleres educativos. Los resultados mostraron que la familia y la escuela se configuran como espacios de conflicto para adolescentes embarazadas. Los dibujos y relatos sobre los sueños de la vida de las adolescentes embarazadas reflejaban sobre la importancia de la función educativa de las enfermeras en la vida de los adolescentes necesitados de atención, información y apoyo.

PALABRAS CLAVE: Adolescentes embarazadas. Sueños de la vida. Papel educativo de las enfermeiras. La escuela y la familia.

ABSTRACT: Curiosity about the topic arises in monitoring the prenatal teens and reflections of a nursing professional acts in the "Family Health Strategy" (ESF). Dreams are presented as a perspective of life which even guarded by pregnant adolescents may contain reflective possibilities for future projections. The aim of the study was to reflect on the dreams of life of pregnant adolescents and the possibilities for educational actions in health. qualitative research, developed through a case study for accessibility, sample type widely used in exploration or qualitative studies, in which the researcher chooses participants who have access. The study was conducted with four pregnant adolescents enrolled in USF of a medium-sized municipality of SC through educational workshops. The results showed that family and school are configured as conflict spaces for pregnant adolescents. The drawings and narratives about the dreams of life of the pregnant adolescents did reflect on the importance of the educational role of nurses in the lives of needy teenagers care, information and support.

KEYWORDS: Pregnant adolescent. Life dreams. Educational role of nurses. School and family.

\section{Introdução}

A curiosidade sobre o tema surge do acompanhamento do pré-natal de adolescentes e de reflexões sobre a prática profissional de uma enfermeira atuante em uma Unidade de Saúde da Família (USF). A prática do enfermeiro no atendimento a esse público se desenvolve, na maioria das vezes, sob a perspectiva técnico-científica e por meio de campanhas de prevenção à gravidez precoce, predominantemente prescritivas, que nem sempre alcançam seus objetivos. A preocupação é ainda maior quando se observa que só depois de grávida, as adolescentes passam a receber um cuidado diferenciado em enfermagem. Assim torna-se importante uma reflexão sobre o papel do enfermeiro como educador, considerando suas perspectivas de atuação junto à mãe adolescente antes e após o parto. Tendo em vista que o papel educativo do profissional da saúde é um dos 
componentes das ações básicas de saúde (FIGUEIREDO, 2005), essa pesquisa se justifica por buscá-lo.

Na adolescência, quando a gestação é muitas vezes encarada como problema por parte da família e das adolescentes, surge a necessidade de pesquisas que aprofundem aspectos que circundam questão tão complexa. De acordo com o Estatuto da Criança e do Adolescente, Lei n. ${ }^{\circ}$ 8069/90, adolescente é todo indivíduo com idade entre 12 e 18 anos, e para a Organização Mundial de Saúde (OMS) esse período envolve indivíduos com idades entre 10 a 19 anos. Nessa faixa etária, além das alterações físicas, observam-se profundas mudanças biopsicossociais, principalmente no que diz respeito à maturação sexual, busca da identidade adulta e autonomia frente aos pais.

No Brasil, entre 20-25\% do total de mulheres gestantes são adolescentes; dentre estas, uma em cada cinco gestantes são adolescentes com idade entre 14 e 20 anos (SANTOS, JÚNIOR, 1999). Nosso país ainda assiste a um aumento do número de adolescentes que engravidam, diferente do que acontece em outros países ocidentais, nos quais tende a ocorrer uma diminuição na ocorrência deste evento (Pesquisa GRAVAD, 2006).

Para compreender a adolescência "é necessário superar as visões naturalizantes presentes na Psicologia e entender a adolescência como um processo de construção sob condições histórico-culturais específicas" (OZELLA, 2003, p. 20). A adolescência pode ser compreendida então como uma categoria construída socialmente, por considerar as necessidades sociais, culturais e econômicas inerentes ao processo de constituição das pessoas.

De qualquer forma, é preciso lembrar que a gravidez na adolescência tornou-se um problema de saúde pública devido ao grande número de gestações e aos impactos que esse processo gera (SILVA, et al, 2009). O problema é assim tratado também pelo fato de propiciar riscos ao desenvolvimento da criança gerada e da própria adolescente (GONTIJO; MEDEIROS, 2004). No entanto, nem sempre a repercussão da gravidez pode ser identificada de forma linear como um fator de risco. Esse fenômeno complexo precisa ser problematizado como um processo e não a partir de um único fator como risco e/ou proteção. Para além de se configurar como um problema social, associado à pobreza e ao comprometimento de um desenvolvimento saudável, estudos atuais sinalizam que a gravidez na adolescência é um fenômeno resultante de múltiplas características e variáveis (CANAVARRO; PEREIRA, 2001).

RIAEE - Revista Ibero-Americana de Estudos em Educação, Araraquara, v. 13, n. 2, p. 822-838, abr./jun., 2018. E-ISSN: $1982-5587$. 
Considerando que o processo da gravidez favorece a reflexão sobre "ser mãe", e por certo envolve crenças, medos, angústias e as relações interpessoais da adolescente, o estudo aqui referenciado se justifica ao buscar refletir sobre os sonhos de vida da gestante adolescente.

Vários estudos realizados com adolescentes em situação de risco têm apontado diferentes significados revelando valores, culturas e crenças dessa população (BRANDÃO; HEILBORN, 2006; GONTIJO; MEDEIROS, 2004, REIS; OLIVEIRA MONTEIRO, 2007). Vale destacar que os sonhos de vida das gestantes adolescentes, de acordo com Levasseur (2013, p. 1):

[...] não podem ser reduzidos a uma semelhança condensada do que o indivíduo experimentou e removido do passado. Eles são um pouco sobre o presente e o exterior do que o passado e a interioridade. Eles representam a constante possibilidade do sujeito se reconectar a uma experiência mais ampla de mundo.

Os sonhos se apresentam como possibilidades, desejos acalentados de vida. Conforme estudos de Andrade, Ribeiro e Ohara (2009), compreender os sonhos e as expectativas de vida da adolescente é possibilitar ações preventivas em saúde com boas expectativas para projetos de vida futuros. Nesse sentido, o enfermeiro teria um papel fundamental como educador social dessas adolescentes. Para Bettinelli (1998, p. 39), "o profissional de enfermagem deve ter a capacidade de utilizar a intuição e ter uma percepção bastante acurada para poder envolver-se mais durante o cuidado [...]”. Nessa direção, a adolescência tem sido foco de atuação dos mais diversos profissionais, muitos dos quais têm procurado desenvolver ações para favorecer, de modo intencional, uma saudável gravidez na adolescência.

Esse artigo apresenta parte de uma pesquisa ${ }^{3}$ que buscou dentre outros objetivos refletir sobre os sonhos de vida de gestantes adolescentes como possibilidade de se propor ações educativas em saúde.

Considera-se que por meio de ações educativas o sujeito pode tornar-se inteiro, pleno, valorizando suas capacidades. Pode ser esse processo um instrumento de transformação, de construção e reconstrução da realidade, de posturas e de atitudes,

3 Dissertação intitulada "gestantes adolescentes e aprendizagem do autocuidado no contexto da estratégia de saúde da família (esf) em Lages (SC)" apresentada junto ao Programa de Pós-graduação em Educação (PPGE) da Universidade do Planalto Catarinense UNIPLAC, 2014. 
tornando o mundo e a história mais humanos (ZAMPIERI et al, 2010, p. 720). Sendo assim, não se pode tratar a gestante adolescente apenas como uma parte de um processo, no qual se divide cuidados fisiológicos, físicos e de bem estar apenas do corpo, pois a gestação é um processo que traz muitas modificações, principalmente emocionais e sociais. Nesta ótica, a Teoria da Complexidade de Morin (2003, p.17) colabora ao esclarecer que o ser humano é trinitário, pois é indivíduo, membro de uma espécie biológica, e de seres sociais, concebendo o ser humano em sua multidimensionalidade.

\section{Percurso metodológico do estudo}

Tratou-se de uma pesquisa de caráter qualitativo, desenvolvida por meio de um estudo de caso. Segundo Lüdke e André (1986), o estudo de caso é algo singular, rico em dados descritivos, e focaliza a realidade de forma complexa e contextualizada. Para as autoras, esse procedimento se caracteriza pela sua capacidade de descoberta a partir da interpretação da realidade.

A definição da amostra se deu por acessibilidade (GIL, 1999): quatro gestantes cadastradas numa UBS (Unidade Básica de Saúde) de um município de médio porte de SC concordaram em participar. Considerando que as atividades propostas pela oficina educativa seriam desenvolvidas numa UBS, uma autorização foi solicitada à Secretaria Municipal de Saúde. Respeitando os aspectos éticos da pesquisa, encaminhamos o projeto de estudo ao Comitê de Ética em Pesquisa (CEP) da Universidade do Planalto Catarinense (UNIPLAC), onde o mesmo foi aprovado sob o $\mathrm{n}^{\mathrm{o}}$. de protocolo 085/2013. Após esses encaminhamentos, apresentamos o Termo de Consentimento Livre e Esclarecido a cada responsável pela gestante adolescente, sendo o mesmo assinado após a manifestação individual de cada uma delas.

A oficina pedagógica foi a estratégia utilizada para desvelar os sonhos de vida de cada participante. Esse tipo de oficina, nesse estudo nomeada de "oficina educativa", refere-se ao "[...] âmbito de reflexão e ação no qual se pretende superar a separação que existe entre a teoria e a prática, entre conhecimento e trabalho e entre a educação e a vida". (OMISTE; LÓPEZ; RAMÍREZ, 2000, p. 178). A oficina educativa foi composta por dois momentos: no primeiro momento foi solicitado a cada uma das participantes que desenhassem seu sonho de vida, visto como uma representação pedagógica. O segundo 
momento foi o da narrativa. Nele, as adolescentes, por meio de conversa com a pesquisadora, falaram sobre os seus sonhos de vida.

Para garantir o sigilo na divulgação dos dados e problematização dos relatos, pedimos às gestantes adolescentes que indicassem nomes de cantoras que lhes fizessem sentido.

Quadro 1: Descrição dos Codinomes

\begin{tabular}{|c|c|c|c|c|}
\hline $\begin{array}{ll}\text { Ordem } & \text { da } \\
\text { Entrevista } & \\
\end{array}$ & $\begin{array}{l}\text { Nome } \\
\text { Cantora }\end{array}$ & $\begin{array}{l}\text { Estilo } \\
\text { Musical }\end{array}$ & Características & $\begin{array}{l}\text { Associação da cantora } \\
\text { com a entrevistada }\end{array}$ \\
\hline $1^{\text {a }}$ Entrevistada & Anitta & Funk & $\begin{array}{lr}\text { Perfil: } & \text { Espontânea, } \\
\text { extrovertida, } & \text { "menina } \\
\text { moleca" } & \text { (site: } \\
\text { http://anittaoficial.com.br/) }\end{array}$ & $\begin{array}{ll}\text { Demonstra } & \text { um lado } \\
\text { espontâneo, despojado, } \\
\text { decidida. }\end{array}$ \\
\hline $2^{\text {a }}$ Entrevistada & $\begin{array}{l}\text { Paula } \\
\text { Fernandes }\end{array}$ & Sertanejo & $\begin{array}{l}\text { Perfil: discreto } \\
\text { (site: } \mathrm{g} 1 . c o m . b r)\end{array}$ & $\begin{array}{l}\text { Demonstra um lado } \\
\text { introvertido }\end{array}$ \\
\hline $3^{\text {a }}$ Entrevistada & $\begin{array}{l}\text { Maria } \\
\text { Cecília }\end{array}$ & $\begin{array}{l}\text { Sertanejo } \\
\text { Universitário }\end{array}$ & $\begin{array}{l}\begin{array}{l}\text { Perfil: Muito sensível e } \\
\text { carismática }\end{array} \\
\text { http://amortransparente.wor } \\
\text { dpress.com/biografia/ }\end{array}$ & Demonstra tranquilidade \\
\hline $4^{\text {a }}$ Entrevistada & $\begin{array}{l}\text { Roberta } \\
\text { Miranda }\end{array}$ & Sertanejo & 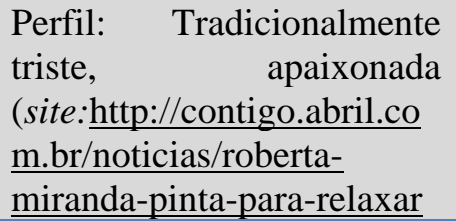 & Apaixonada \\
\hline
\end{tabular}

Fonte: Elaboração própria

O método escolhido para analisar os dados coletados na oficina educativa foi a análise de conteúdo, no qual o tratamento dos dados busca elucidar informações para além da fala dos participantes. Conforme Bardin (2006, p. 44), a análise de conteúdo pode ser definida como:

Um conjunto de técnicas da análise de comunicação visando obter por procedimentos sistemáticos e objetivos de descrição do conteúdo das mensagens indicadores (quantitativos ou não) que permitam inferência de conhecimentos relativos às condições de produção/recepção (variáveis inferidas) destas mensagens.

A análise de conteúdo abrange as iniciativas de explicitação, sistematização e expressão do conteúdo de mensagens, com a finalidade de se efetuarem deduções lógicas e justificadas a respeito da origem dessas mensagens: quem as emitiu, em que contexto e/ou que efeitos se pretende causar por meio delas (CAPPELLE; MELO; GONÇALVES, 2003). 
Segundo Bardin (2006), o método da análise de conteúdo tem como principais objetivos: a ultrapassagem da incerteza, o enriquecimento da leitura, a verificação prudente ou uma interpretação brilhante. Assim, a análise dos dados desenhados pelas adolescentes foi uma análise dos significados (análise temática), que buscou identificar conteúdos ou temas.

\section{Perfil das gestantes adolescentes}

Quadro 2: Perfil das Gestantes Adolescentes

\begin{tabular}{|c|c|c|c|c|c|c|}
\hline $\begin{array}{l}\text { Ordem } \\
\text { das } \\
\text { Entrevis } \\
\text { tas } \\
\end{array}$ & Codinome & Idade & $\begin{array}{l}\text { Idade } \\
\text { Gestacional } \\
\text { (meses) }\end{array}$ & $\begin{array}{l}\text { Frequenta } \\
\text { Escola }\end{array}$ & Trabalha & $\begin{array}{l}\text { Mora com } \\
\text { quem? }\end{array}$ \\
\hline $\begin{array}{l}1^{\mathrm{a}} \\
\text { Entrevis } \\
\text { tada }\end{array}$ & Anitta & 15 anos & 3 meses & $\begin{array}{l}\text { Não/ medo de } \\
\text { perder o bebê }\end{array}$ & $\begin{array}{l}\text { Não/ por } \\
\text { causa da idade }\end{array}$ & $\begin{array}{l}\text { Sogra, } \\
\text { companheiro } \\
\text { e cunhada }\end{array}$ \\
\hline $\begin{array}{l}2^{a} \\
\text { Entrevis } \\
\text { tada }\end{array}$ & $\begin{array}{l}\text { Paula } \\
\text { Fernandes }\end{array}$ & 18 anos & 6 meses & $\begin{array}{l}\text { Não/ não quis } \\
\text { mais estudar }\end{array}$ & Não & Mãe e irmãos \\
\hline $\begin{array}{l}3^{\mathrm{a}} \\
\text { Entrevis } \\
\text { tada }\end{array}$ & $\begin{array}{l}\text { Maria } \\
\text { Cecília }\end{array}$ & 16 anos & 8 meses & $\begin{array}{l}\text { Não/ } \\
\text { implicância" da } \\
\text { escola }\end{array}$ & Não & $\begin{array}{l}\text { Mãe, pai e } \\
\text { irmãs }\end{array}$ \\
\hline $\begin{array}{l}4^{\mathrm{a}} \\
\text { Entrevis } \\
\text { tada }\end{array}$ & $\begin{array}{l}\text { Roberta } \\
\text { Miranda }\end{array}$ & 19 anos & 5 meses & Não/ preguiça & Não & $\begin{array}{l}\text { Companheiro } \\
\text { e filho }\end{array}$ \\
\hline
\end{tabular}

Fonte: Elaboração própria.

O Quadro contém muitos significados relacionados ao perfil de cada participante. Em relação à categoria de codinome sugerido pela entrevistadora, uma cantora, cada adolescente indicou o nome daquela com quem se identificava, permitindo uma primeira aproximação de seu perfil. A primeira entrevistada, "Anitta", revelou um lado despojado, alegre, decidido. Já a segunda, "Paula Fernandes", uma característica introvertida. Por sua vez, "Maria Cecília", a terceira entrevistada, mostrou tranquilidade. E "Roberta Miranda", a quarta, um perfil apaixonado. Essa associação estratégica utilizada pelas pesquisadoras exigiu uma prévia busca de sites que descrevessem o perfil das referidas cantoras.

Em relação à idade gestacional, observa-se que variou bastante: do $1^{\circ}$ ao $3^{\circ}$ trimestre de gestação, com cada adolescente gestante experimentando sensações diferentes relacionadas a esse momento. Tendo em vista a idade das participantes, Anita, Paula Fernandes e Maria Cecília deveriam estar frequentando a escola, mas não estavam. Observamos também nos depoimentos a desmotivação das meninas quanto aos estudos. 
Roberta Miranda, de 19 anos, já está na segunda gestação e declarou que “[...] ter um filho de 1 (um) ano e ter uma casa para gerenciar traz muitas responsabilidades; sendo assim, os estudos ficaram em segundo plano".

Com relação ao convívio familiar, Paula Fernandes e Maria Cecília destacaram que moram com os pais e que de alguma forma recebem apoio deles. Anita preferiu morar com a sogra e com o namorado, e não mencionou se os pais a estão apoiando neste momento. Roberta Miranda mora com o esposo e o filho, tem uma união estável e afirmou que apenas o esposo trabalha, sendo de sua responsabilidade os afazeres domésticos.

No que diz respeito ao trabalho, nenhuma delas se encontra inserida em alguma atividade remunerada. Anitta disse que não trabalha fora porque é muito nova; Roberta Miranda, porque precisa cuidar do filho e da casa; já Paula Fernandes e Maria Cecília não viram importância nessa questão e afirmaram que neste momento sua preocupação é com a gestação.

\section{Compreendo os sonhos de vida da gestante adolescente}

Esse foi o momento da escuta para a compreensão dos sonhos de vida, visando não apenas amparo no período da gestação, mas uma escuta sensível dos projetos de vida futura dessas adolescentes, tendo em vista a proposição de ações educativas em saúde.

Buscando a compreensão dos sonhos de vida das gestantes adolescentes, solicitamos que elas elaborassem, durante a "oficina educativa", um desenho de grande significado para si. Nesses desenhos, pudemos identificar conteúdos importantes e o valor dos sonhos para cada uma delas.

Anitta e Maria Cecília relataram que o seu sonho de vida era ser professora, relacionaram esse sonho à possibilidade de auxiliar as crianças na construção de conhecimento. Essa seria uma perspectiva de futuro para as suas vidas. Para Foucault (1994), o sonho é um sinal de transcendência acessível, um movimento original de liberdade em relação ao mundo que representa para o sujeito a experiência mais radical. Os sonhos permitem uma ampliação da relação com o mundo e consigo mesmo. Dessa maneira, apresentaram uma reflexão sobre a própria construção de vida.

Quando Anitta e Maria Cecília mencionaram que seu sonho de vida era ser professora, deixaram claro que vislumbravam um processo de construção do presente e do futuro. A escola é espaço de construção de significados, é um caminho importante para que 
os adolescentes transformem a si mesmos e ao seu redor, a partir do seu desenvolvimento pessoal (ser), social (conviver), produtivo (fazer) e cognitivo (aprender), conforme os 4 Pilares da Educação para o Século 21, da UNESCO (DELORS, 2001). Por outro lado, os sonhos de vida das gestantes adolescentes permitiram o diálogo da pesquisadora com o pensamento complexo (MORIN, 2006), por focalizarem o sonho de vida como possibilidade para o agir.

Para Paula Fernandes e Roberta Miranda, os sonhos de vida as remetiam a ter a casa própria e constituir uma família. Os sonhos nos constituem e mostram o que queremos em relação a nós mesmos. O sonho diz algo sobre o ser e a vida de quem sonha (FOUCAULT, 2006, p. 121). A escola e a família são espaços privilegiados de socialização e humanização, processos indispensáveis ao planejamento de projetos pessoais e sociais de cada um. "Família e escola são os ambientes de excelência, onde deverão se desenvolver as condições mais propícias para a formação integral do adolescente, com vistas ao seu desenvolvimento harmônico" (CASASANTA, 1998).

$\mathrm{Na}$ parte da narrativa sobre o desenho, as adolescentes tiveram oportunidade de prosseguir na reflexão sobre suas vidas. Em seu desenho, Anitta destacou também o sonho da casa própria para que pudesse morar com o seu filho, fez a representação da ideia de reunião ao desenhar um espaço para ter a sua família organizada num ambiente afetivo e acolhedor. A família fundamentou seu sonho de vida mostrando seu desejo de desenvolver o seu próprio modelo de socialização e reconstrução de sua vida social. A família como base de reflexão, espaço onde o adolescente se constitui. Segundo Dessen e Polonia (2007, p. 22), "a família é matriz da aprendizagem humana, com significados e práticas culturais próprias que geram modelos de relação interpessoal e de construção individual e coletiva".

De acordo com os autores, a família, presente em todas as sociedades, é um dos primeiros ambientes de socialização do indivíduo, atuando como mediadora principal dos padrões, modelos e influências culturais. É no âmbito familiar que o adolescente aprende a lidar com as diferentes situações e expressa os diferentes sentimentos, para se constituir como membro de uma sociedade.

É por meio das interações familiares que se concretiza as transformações nas sociedades que, por sua vez, influenciarão as relações familiares futuras, caracterizando-se por um processo de influências bidirecionais, entre os membros familiares e os diferentes ambientes que compõem os sistemas sociais (DESSEN; POLONIA, 2007, p. 22). 
Paula Fernandes, por sua vez, comentou o desenho que fez sobre seu sonho de vida, no qual representava a casa própria e a escola. Essa representação indicava a importância da família e da escola como eixos centrais de sua vida. Uma articulação necessária para a sua felicidade.

Para Menezes (2003, p. 45), "o sonho é o devir ocorrendo, o primeiro momento da liberdade se liberando, a convulsão, ainda secreta, de uma existência que se reintegra no conjunto do seu devir". O sonho contribui para o autorreconhecimento da gestante adolescente, reflexões que dão sustento a planos futuros.

Segundo Foucault (1994, p. 82):

O sonho, como toda experiência imaginária, é, desse modo, uma forma específica de experiência que não se deixa reconstituir inteiramente pela análise psicológica, cujo conteúdo designa o homem como ser transcendente. O imaginário emerge como signo da transcendência; e o sonho, como experiência desta transcendência sob o signo do imaginário.

Podemos então compreender que como primeira mediadora entre o homem e a cultura, a família constitui a unidade dinâmica das relações de cunho afetivo, social e cognitivo que estão imersas nas condições materiais, históricas e culturais de um dado grupo social. Os acontecimentos e as experiências familiares propiciam a formação de repertórios comportamentais, de ações e resoluções de problemas com significados universais (DESSEN; POLONIA, 2007).

Para Wagner et al (1999), no âmbito familiar, a criança aprende a administrar e resolver os conflitos, a controlar as emoções, a expressar os diferentes sentimentos que constituem as relações interpessoais, a lidar com as diversidades e adversidades. Os desenhos mostraram que as adolescentes sentiam-se seguras no seio da família.

A escola como instância formadora também exerce grande influência nas tomadas de decisões e no desenvolvimento do adolescente como um ser pensante e capaz de criar e recriar sua história. De acordo com Mahoney (2002), a escola constitui um contexto diversificado de desenvolvimento e aprendizagem, um local que reúne diversidade de conhecimentos, atividades, regras e valores e que é permeado por conflitos, problemas e diferenças. Assim, a família e a escola se destacaram nos sonhos e projetos futuros de vida das adolescentes.

De acordo com Boff (2005), "somente aquilo que passou por uma emoção, que evocou um sentimento profundo e provocou cuidado em nós, deixa marcas indeléveis e permanece definitivamente". Assim como nas indicações das adolescentes grávidas 
emergiram como categorias temáticas a casa própria e a escola associadas à ideia de vida tranquila.

O sonho de Maria Cecília também destacava a escola como espaço para estudar, refletir sobre o mundo e si mesma. A escola, local em que mais tarde seria o espaço escolhido por ela para trabalhar e contribuir com a formação de outros adolescentes, conforme relatado na narrativa do desenho. Seu sonho de vida continha também projeções profissionais futuras. As Diretrizes Curriculares Nacionais fazem referência à formação geral e profissional:

[...] missão fundamental da educação consiste em ajudar cada indivíduo a desenvolver todo o seu potencial e a tornar-se um ser humano completo, e não um mero instrumento da economia; a aquisição de conhecimentos e competências deve ser acompanhada pela educação do caráter, a abertura cultural e o despertar da responsabilidade social. (BRASIL, 1998, p. 59).

Assim, o sonho de Maria Cecília se articula a esse referencial que nos lembra bem a educação do homem por inteiro. Ao desenhar a escola, a adolescente acrescentou características de amplitude e organização. A sala de aula do desenho chamou-nos a atenção pela disposição das cadeiras sob a forma de círculo. O sistema escolar, além de envolver uma gama de pessoas com características distintas, inclui um número significativo de interações contínuas e complexas em função dos diferentes estágios de desenvolvimento desses alunos. Trata-se de um ambiente multicultural que abrange também a construção de laços afetivos e preparo para inserção na sociedade (OLIVEIRA, 2000). As cadeiras em círculo podem também significar uma escola inclusiva, que pela contribuição do pensamento complexo coloca professores, pais, alunos, especialistas, pesquisadores como uma rede de apoio à inclusão da diferença. A adolescente parece indicar a necessidade de se reconstruir modelos de escola e de educação para propor outras lógicas.

Dessen e Polonia (2007) destacam que a escola, sendo um microssistema da sociedade, não apenas reflete as transformações atuais como também expressa diferentes demandas do mundo globalizado. Uma de suas tarefas é sensibilizar tanto alunos quanto professores e pais para enfrentarem as dificuldades de um mundo de mudanças rápidas e de conflitos interpessoais, raciais, de gênero e tantos outros.

De acordo com Oliveira (2004, p. 109): 
Do ponto de vista educacional o processo de inclusão deve ser capaz de atender a todos, indistintamente, sendo capaz de incorporar as diferenças no contexto da escola o que exigirá a transformação de seu cotidiano e, certamente, o surgimento de "novas formas de organização escolar, audaciosas e comprometidas com uma nova forma de pensar e fazer educação".

$\mathrm{O}$ atendimento às necessidades educacionais extrapola a esfera meramente escolar e atinge todas as instâncias sociais, desde os setores de saúde e assistência social até o âmbito familiar (OLIVEIRA; LEITE, 2007, p. 514). Neste sentido, os processos educativos podem contribuir para que as gestantes adolescentes valorizem suas capacidades, reconstruam sua realidade e se realizem não somente como mãe, mas também como seres sociais ativos. O que corrobora a afirmação de Zampieri et. al. (2010, p. 720), ao refletirem sobre os processos educativos:

Pode contribuir para a autonomia no agir, possibilitando aos envolvidos tornarem-se sujeitos ativos, na medida em que contribui para valorizar capacidades, auto-estima, autoconfiança e auto-realização. Um instrumento de transformação, de construção e reconstrução da realidade, de posturas e de atitudes, tornando o mundo e a história mais humanos. Visa resgatar a condição de sujeito, a vocação ontológica do homem na busca de "ser mais" e de se humanizar.

Os sonhos de vida relatados e trabalhados numa relação mediadora podem contribuir na reflexão sobre o desenvolvimento dos processos educativos em saúde por permitirem que o enfermeiro, como Educador Social, auxilie no desenvolvimento da autonomia e vida futura das gestantes adolescentes.

O desenho de Roberta Miranda, rico em detalhes, como flores no jardim, janelas com cortinas, balanço ao lado da casa, mostrava seu sonho de viver em um ambiente acolhedor e agradável.

Para Dessen e Polonia (2007), a família não é entendida como um sistema privativo de relações, pelo contrário, as atividades individuais e coletivas estão intimamente ligadas e se influenciam mutuamente. Ela é responsável também pela transmissão de valores, compartilhamento de regras, sonhos, perspectivas e padrões de relacionamento, bem como a valorização do potencial dos seus membros e de suas habilidades de acumular, ampliar e diversificar as experiências.

Tendo em vista o significado atribuído aos sonhos de vida por cada uma das gestantes adolescentes percebemos que o processos educativos em saúde podem auxiliar o 
enfermeiro na reconstrução de possibilidades de vida futura para essas gestantes adolescentes.

Apoiadas no pensamento complexo de Morin (2006), observamos que os sonhos de vida dessas adolescentes sinalizaram a incompletude do processo de construção contínua do ser humano. Em consonância com o Pensamento Complexo, a prática educativa exprime a ideia de uma prática horizontal do conhecimento que proporciona mudança na realidade, pois, "todo conhecimento é uma reconstrução/tradução feita por uma mente/cérebro, em uma cultura e época determinadas". (MORIN, 2000, p. 93-6).

As traduções realizadas pelas adolescentes indicavam sonhos, preocupações e desejos. Os sonhos de vida surgiram como pistas para estratégias educativas de apoio a gestantes adolescentes em suas projeções futuras e a estratégias educativas em saúde.

\section{Considerações provisórias sobre o estudo}

Dentro das possibilidades da pesquisa qualitativa procuramos desenvolver uma perspectiva metodológica diferenciada para problematizar os sonhos de vida das gestantes adolescentes. A estratégia foi eficiente na medida em que as adolescentes expressaram nos desenhos suas percepções a respeito dos sonhos de vida, indicando a necessidade de ampliamos o nosso olhar sobre a realidade estudada, onde família e escola configuram-se como espaços de relações e conflito para as gestantes adolescentes.

Os desenhos e narrativas sobre os sonhos de vida das gestantes adolescentes permitiram a reflexão sobre a humanização de espaços como a escola e família. Nesse sentido, o enfermeiro tem um papel educativo fundamental. Como sensibilizar as famílias para o acolhimento das gestantes adolescentes? Como criar espaços legítimos de relatos e escuta que favoreçam à humanização sua potência reveladora e transformadora (BRASIL, 2005)?

Os sonhos desvelaram os desejos mais íntimos, que ficam esquecidos ou guardados no inconsciente. A cada desenho, a evidência de que o sonho de vida é também gerador de esperança na melhoria de suas relações no contexto familiar e escolar. As adolescentes sonham com uma escola inclusiva, capaz de reconhecer diferenças, favorecer a construção da autonomia do sujeito e de acolhimento à gravidez na adolescência.

Observou-se ao longo do estudo que todas as adolescentes, por motivos diferentes, encontravam-se fora da escola no momento de suas gestações. Afinal, qual seria 
o papel da escola na vida dessa adolescente grávida? Ao considerar a situação de vulnerabilidade social dessas adolescentes, a comunidade escolar poderia apoiar a não desistência dos sonhos, auxiliando-as no processo de reconstrução do contexto social, familiar, educacional e de saúde.

Durante a oficina educativa, as gestantes adolescentes expressaram sua vontade de retornar à escola, de onde se afastaram no período da gravidez. Também manifestaram o desejo de trabalhar, de buscar sua inserção na sociedade, de ter reconhecimento profissional, indícios de responsabilidade para com o bebê que irá nascer, e também da necessidade de assumirem seu papel cidadã com capacidade para decidir o que é melhor para si mesmas.

Morin (2006) afirma que não podemos separar o "uno do múltiplo e o múltiplo do uno". É preciso compreender a adolescente grávida de forma circular, onde todas as condicionalidades de seu desenvolvimento possam ser identificadas e consideradas. Nesse sentido, convém repensarmos estratégias de educação em saúde na escola como forma de capacitar professores e adolescentes sobre o tema, sensibilizando-os para a compreensão do fenômeno gravidez na adolescência.

Percebendo a complexidade das relações familiares e das escolas no enfrentamento da gestação na adolescência, destacamos a importância do papel do enfermeiro na saúde dos adolescentes carentes de cuidados, informações e apoio (SIQUEIRA et al., 2005). É possível pensar práticas saudáveis que integrem família, escola e outros setores sociais na busca de ações que visem o empoderamento dessas adolescentes grávidas. Nesse sentido, convém ter cautela para não legitimar práticas assistencialistas que levam à apatia e à não participação social. Que possamos investir em políticas públicas com ações que sustentem processos de autonomia e mudança do curso de vida, para que essas adolescentes consigam se impor como sujeitos participativos e autodeterminados.

\section{REFERÊNCIAS}

ANDRADE P. R.; RIBEIRO C. A.; OHARA C. V. S. Maternidade na adolescência: sonho realizado e expectativas quanto ao futuro. Rev Gaúcha Enferm, Porto Alegre, v. 30, n. 4, p. 662-668.

BARDIN, L. Análise de conteúdo. (L. de A. Rego \& A. Pinheiro, Trads.). Lisboa: Edições 70, 2006. 
BRASIL. Diretrizes Nacionais para a Atenção Integral à Saúde de Adolescentes e Jovens na Promoção, Proteção e Recuperação da Saúde, 2010. Disponível em: <http://dab.saude.gov.br/atencaobasica.php>. Acesso em: 05 mar. 2013.

BRASIL. Ministério da Saúde. A educação permanente entra na roda: pólos de educação permanente em saúde, Brasília, DF, 2005. Disponível em:

<http://bvsms.saude.gov.br/bvs/publicacoes/educacao_permanente_entra_na_roda.pdf>. Acesso em: 24 jun. 2012.

BOFF, L. O cuidado essencial: princípio de um novo ethos. Inclusão Social, Brasília, v. 1, n. 1, p. 28-35, out./mar., 2005.

BRANDÃO, E. R.; HEILBORN, M. L. Sexualidade e gravidez na adolescência entre jovens de camadas médias do Rio de Janeiro, Brasil. Caderno de Saúde Pública, v. 2, n. 7, p. 1421-1430, 2006.

DELORS, J. et al. Educação: um tesouro a descobrir. Relatório para a UNESCO da Comissão Internacional sobre a Educação para o século XXI. $8^{a}$ ed. São Paulo: Cortez Editora; Brasília, DF: MEC: UNESCO, 2001.

CANAVARRO, M. C.; PEREIRA, A. I. Gravidez e maternidade na adolescência: perspectivas teóricas. In: CANAVARRO, M. C. (Ed.). Psicologia da gravidez e da maternidade. Coimbra: Quarteto Editora, 2001.

CAPPELLE, M. C. A.; MELO, M. C. O. L.; GONÇALVES, C. A. Análise de conteúdo e análise de discurso nas ciências sociais. Organizações Rurais \& Agroindustriais, v. 5, n. 1, p. 2003.

CORBANI, N. M. S.; BRETAS, M. C. P.; MATHEUS, M. C. C. Humanização do Cuidado de Enfermagem: o que é isso. Revista Brasileira de Enfermagem. Brasília: v. 62, n. 3, p. 349-354, maio/jun., 2009.

COSTA, A. P. M. Os adolescentes e seus direitos fundamentais: da invisibilidade à indiferença. Porto Alegre: Livraria do advogado Editora, 2012.

DESSEN, M. A.; POLONIA, A.C. A Família e a Escola como Contextos de Desenvolvimento Humano. Paidéia, 2007.

DIAS, A. C. G.; GOMES, W. B. Conversas, em família sobre sexualidade e gravidez na adolescência: percepção das jovens gestantes. Universidade Federal do Rio Grande do Sul, 2003.

FIGUEIREDO, N. M. A. Ensinando a cuidar em saúde Pública. São Caetano do Sul, 2005.

FOUCAULT, M. Introduction, in Dits et Écrits. v. 1, ed. Gallimard, 1994. 
GONTIJO, D. T.; MEDEIROS, M. A gravidez/maternidade e adolescentes em situação de risco social e pessoal: algumas considerações. Revista Eletrônica de Enfermagem, v.3, n. 6, 2004.

LEVASSEUR, C. O Sonho por Michel Foucault. Disponível em: <http://www.enewsterrassa.com/o-sonho-por-michel-foucault-resenha.html>. Acesso em: 10 jan. 2014.

LÜDKE, M.; ANDRÉ, M. E. D. A. Pesquisa em educação: abordagens qualitativas. São Paulo: E.P.U., 1986.

MAHONEY, A. A. Contribuições de H. Wallon para a Reflexão sobre as Questões Educacionais. In: PLACCO, V. S. (Org.). Psicologia e Educação: revendo contribuições. São Paulo, 2002: Educ. p. 9-32.

MORIN, E. Eliane Lisboa (trad). Introdução ao pensamento complexo. Porto Alegre: Sulina, 2006.

MENEZES, J. E. X. A Psicanálise e a Psicologia: o exame crítico do primeiro Foucalt. Tese de Doutorado. Universidade Estadual de Campinas. 2013.

OLIVEIRA, A. A. S.; LEITE, L. P. Construção de um Sistema Educacional Inclusivo: um desafio político-pedagógico. Revista Ensaio: avaliação políticas públicas educacionais. Rio de Janeiro, v. 15. n. 57, 2007, out./dez., p. 511-524.

OLIVEIRA, H. M.; GONÇALVES, M. J. F. Educação em saúde: uma experiência transformadora. Revista Brasileira de Enfermagem, Brasília (DF), v. 57, n. 6, p. 761763, 2004.

OLIVEIRA, Z. M. R. Interações Sociais e Desenvolvimento: a perspectiva sociohistórica. Caderno do CEDE, 20, p. 62-77, 2000.

OMISTE, A. S.; LÓPEZ, M. Del C.; RAMIREZ, J. Formação de grupos populares: uma proposta educativa. In.: CANDAU, V. M.; SACAVINO, S. (Org.) Educar em direitos humanos: construir democracia. Rio de Janeiro: DP\&A, 2000.

OZELLA, S. (Org). Adolescências construídas - a visão da psicologia sócio-histórica. São Paulo: Cortez, 2003.

SILVA, V.; Mattos, H. Os jovens são mais vulneráveis às drogas?. In: PINSKY, I.; BESSA, M. A. (Orgs.). Adolescência e drogas. São Paulo: Contexto, 2004. p. 31-44.

Pesquisa GRAVAD (2006). Pesquisa de Adolescentes no Brasil. Disponível em: <www.portal.saude.gov.br>. Acesso em: 10 jun. 2012.

REIS, A.; OLIVEIRA-MONTEIRO, N. Sexualidade e procriação na ótica de jovens de periferias sociais e urbanas. Revista Brasileira Crescimento Desenvolvimento Humano, v. 17, p. 54-63, 2007. 
SANTOS JÚNIOR. Fatores etiológicos relacionados à gravidez na adolescência:

Vulnerabilidade à maternidade. In.: SCHOR, N.; MOTA, M. S.; BRANCO, V. C. (Org.). Cadernos juventude, saúde e desenvolvimento. Brasília: Ministério da Saúde. p. 223229.

SILVA, I. J. et al. Cuidado, Autocuidado e Cuidado de Si: uma compreensão paradigmática para o cuidado em enfermagem. Revista Escola de Enfermagem USP, v. 43, n. 3, p. 697-703, 2009.

ZAMPIERI, M. F. M. et al. Processo educativo com gestantes e casais grávidos: possibilidade para transformação e reflexão da realidade. Texto e Contexto Enfermagem, Florianópolis, v. 19, n. 4, p. 719-727, out./dez., 2010.

\section{Como citar este artigo:}

ARRUDA, Marina Patricio de.; MORAES, Nayara Alano. Sonhos de vida da gestante adolescente: reflexões sobre o papel educativo do enfermeiro. Revista Ibero-Americana de Estudos em Educação, Araraquara, v. 13, n. 2, p. 822-838, abr./jun., 2018. E-ISSN: 1982-5587. DOI: 10.21723/riaee.v13.n2.2018.9537

Submissão em: 17/03/2017

Aprovação final em: 06/06/2017 